\title{
Feasibility study on new energy multi-feed direct current grid connection
}

\author{
Yonghui Guo MEng \\ Doctoral student, Institute of Electrical Engineering, Xinjiang University, \\ Urumqi, China \\ Xinyan Zhang PhD \\ Professor, Institute of Electrical Engineering, Xinjiang University, Urumqi, \\ China (corresponding author: xjcxzxy@126.com)
}

\author{
Liwei Zhao MEng \\ Assistant Lecturer, Institute of Electrical Engineering, Xinjiang University,
} Urumqi, China

To adapt to the characteristics of new energy long-distance transmission, this paper proposes a scheme of multi-fed voltage source converter grid connection and line-commutated converter transmission for a regional large energy base. First, the feasibility of this multi-infeed direct current (DC) transmission scheme is discussed. Then, the performance characteristics of the multi-infeed DC and other traditional transmission technologies are compared and analysed. In addition, the economic benefits of the multi-infeed DC project are evaluated. To study the characteristics of new energy multi-infeed DC power transmission mode, a long-distance energy transmission system based on multi-infeed DC power transmission mode is built using DlgSilent software. On the basis of the continuous power flow method, the static characteristics of the system are studied. Based on the time-domain simulation method, the transient characteristics of the system are studied. The results show that multi-infeed DC has great advantages in large-scale regional new energy long-distance transmission.

\section{Notation \\ $C_{\mathrm{cs}} \quad$ investment in infrastructure equipment such as converter station and transformer station \\ $C_{\text {eng }} \quad$ total project cost \\ $C_{\text {line }} \quad$ average cost per kilometer of transmission line \\ $C_{\text {opti }} \quad$ engineering annual maintenance cost \\ $C_{\text {year }}$ annual fee \\ $c_{\text {invest }}$ annual average of engineering current rate \\ $D_{\text {line }} \quad$ length of transmission line \\ $h_{\text {year }} \quad$ annual utilisation hours of the transmission channel \\ $L_{\mathrm{al}} \quad$ corona loss of line \\ $L_{\text {Rline }} \quad$ loss caused by line resistance during transmission \\ $L_{\mathrm{scl}} \quad$ line loss caused by series compensation capacitance \\ $L_{\text {Tcap }} \quad$ transmission capacity of line \\ $L_{\text {trayear }}$ annual transmission total loss \\ $p \quad$ selling electricity price \\ $T_{\text {conrat }} \quad$ loss rate of commutation/substation}

\section{Introduction}

China's energy distribution is extremely uneven. The demand for electricity in coastal developed areas continues to grow rapidly but the power supply is insufficient. The centralised development of a large number of new energy resources in the Sanbei area has led to the saturation of local consumption and the urgent need for energy export (Shu et al., 2017). The three northern regions have formed a large number of regional energy bases, but the geographical distances between the different energy bases are relatively long, and the exchange and grid connection losses are high, the cost is large and it is not stable enough (Yao et al., 2014). Flexible direct current (DC) transmission technology for grid connection of new energy islands has rapidly developed, but with a small transport capacity (Li et al., 2018). The traditional grid commutationtype DC transmission technology is still the backbone of the future due to its large transmission capacity, high voltage level and low long-distance transmission loss (Li et al., 2016). The new energy is connected to the line-commutated converter (LCC) through the voltage source converter (VSC) and then connected to the LCC DC channel. Compared with the traditional alternating current (AC) grid connection, it has the advantages of stable transmission, large capacity and small loss, which can solve the problem of new energy consumption in regional energy bases (Dong et al., 2019).

A large amount of literature has investigated new energy consumption. By improving the peak shaving capacity of the system, building a complete DC transmission project, and rationally configuring the layout and power structure of new energy, the new energy consumption can be improved (Niu et al., 2016). Power grid commutation DC transmission has the advantages of large transmission capacity, the transmission length not being affected by distance, low cost and so on ( $\mathrm{Li}$ et al., 2017). A large number of ultra-high-voltage (UHV) and DC transmission topologies make AC/DC hybrid power systems more and more common. A large number of DC terminals and grid structures interconnected in the form of DC appear in the grid (Tang et al., 2013). Comparing with the traditional DC transmission mode, flexible DC transmission can achieve independent active and reactive power control and 
black start without commutation failure (Zheng et al., 2013). Using VSC flexible DC transmission technology, many wind farms and photovoltaic power stations are joined together to form a regional DC power grid, which promotes the regional complementarity of new energy sources to a certain extent, and then LCC-DC and DC/DC transformers can be used to realise large-scale outward transmission of new energy. This multi-feed DC power grid topology will become an important structure of future DC power grids (Liu et al., 2014a), However, this paper does not demonstrate this in detail. For large-scale wind farms connected to the grid by VSC-DC, the seamless switching between the operation modes of $\mathrm{AC}$ and DC parallel systems can be realised by adjusting their operation control strategies (Li et al., 2015; Wang et al., 2014). However, when many large-scale wind farms are scattered in a large geographical area, multi-infeed DC is more suitable to connect with the grid. The research on multi-infeed DC systems mainly focuses on the important components such as topology, control strategy and converter station. The designed system lacks overall coordination and cannot reflect the dynamic characteristics of each part of the whole system. The AC transmission model and economic analysis method can be improved and applied to flexible DC transmission (Liu et al., 2018). In order to facilitate the advantages of DC transmission and save engineering costs, it is proposed to change the existing $\mathrm{AC}$ line to a DC line. However, the original grid structure and its scale need to be considered in this scheme (Liu et al., 2013; Peng et al., 2017; Yang et al., 2014).

In this study, the regional large-scale energy long-distance transmission system based on multi-infeed DC transmission is discussed comprehensively. First, the feasibility of engineering technology and construction economy of the above scheme are analysed. Then, the static characteristics of the scheme are analysed according to the continuous power flow method. Finally, the dynamic characteristics of the scheme are analysed according to the fault disturbance method.

\section{Feasibility analysis of new energy multi-infeed DC grid connection}

The typical layout of large regional new energy bases in 'Three North' and other regions of China has many problems, such as weak grid structure, limited transmission and so on, which directly leads to difficulties in peak regulation, limited new energy output and blocked new energy transmission (Cao et al., 2014). With the large-scale development of new energy, the total installed capacity of the regional power grid has far exceeded the power load. The rapid development of wind power, heating units and self-contained power sources has aggravated the difficulty of peak shaving in the regional power grid (Liu et al., 2011). With the centralised and large-scale development of wind power and photovoltaic in the region, the installed capacity of new energy continues to increase, and the problem of wind power transmission being restricted by grid structure becomes more and more prominent; at the same time, the instability factor of regional power grid is increased (Xie et al., 2016).

With the centralised and large-scale development of new energy, it is difficult to absorb it locally. Abundant power cannot be transferred by borrowing the original grid structure, but can only be transmitted by a new grid structure, which is delivered by a large-capacity DC channel cluster. The regional single energy base has many new energy power stations from which to collect energy, send it to the receiving end of the large DC channel through the new grid, and then send it to the farther load centre through the DC outgoing channel (Liu et al., 2014b). The new energy grid-connected system is mainly composed of a new energy electric field, flexible DC transmission line or high-voltage $\mathrm{AC}$ transmission line, isolation transformer and grid commutation DC transmission channel. Its structure is shown in Figure 1.

In the regional grid-connected system of the new energy cluster, three schemes are considered for new transmission lines to be sent to the DC outgoing channel.

Scheme 1: new high-voltage AC lines. Due to the long distance and large capacity, the voltage drop is serious, so reactive compensation is needed to raise the voltage. $\mathrm{AC}$ transmission lines are limited to the asynchronous stability of long-distance transmission.

Scheme 2: new LCC DC line. Two converter stations need to be invested, and the AC system is needed to support the start-up of the system. The new energy base is generally far away from the local AC system, which has limitations. The LCC transmitter needs a lot of reactive power compensation, which causes a huge loss of active power and increases the sub-synchronous resonance. These filters and reactive power compensation equipment are too expensive and require high power quality, and are prone to commutation failure.

Scheme 3: new VSC DC line. It also needs to invest in two converter stations. VSC DC system can realise independent control of active and reactive power without external voltage source. It has the advantages of black-start capability, flexible system control, power supply to passive network and easy power flow reversal.

The performance comparison results of the above three grid connection modes are shown in Table 1. Through the analysis of AC transmission technology, flexible DC transmission technology and multi-infeed DC transmission technology (Li et al., 2016, 2018; Yang et al., 2014), the data in Table 1 are obtained. According to Table 1, the performance of the LCC-DC grid connection mode is far lower than other 


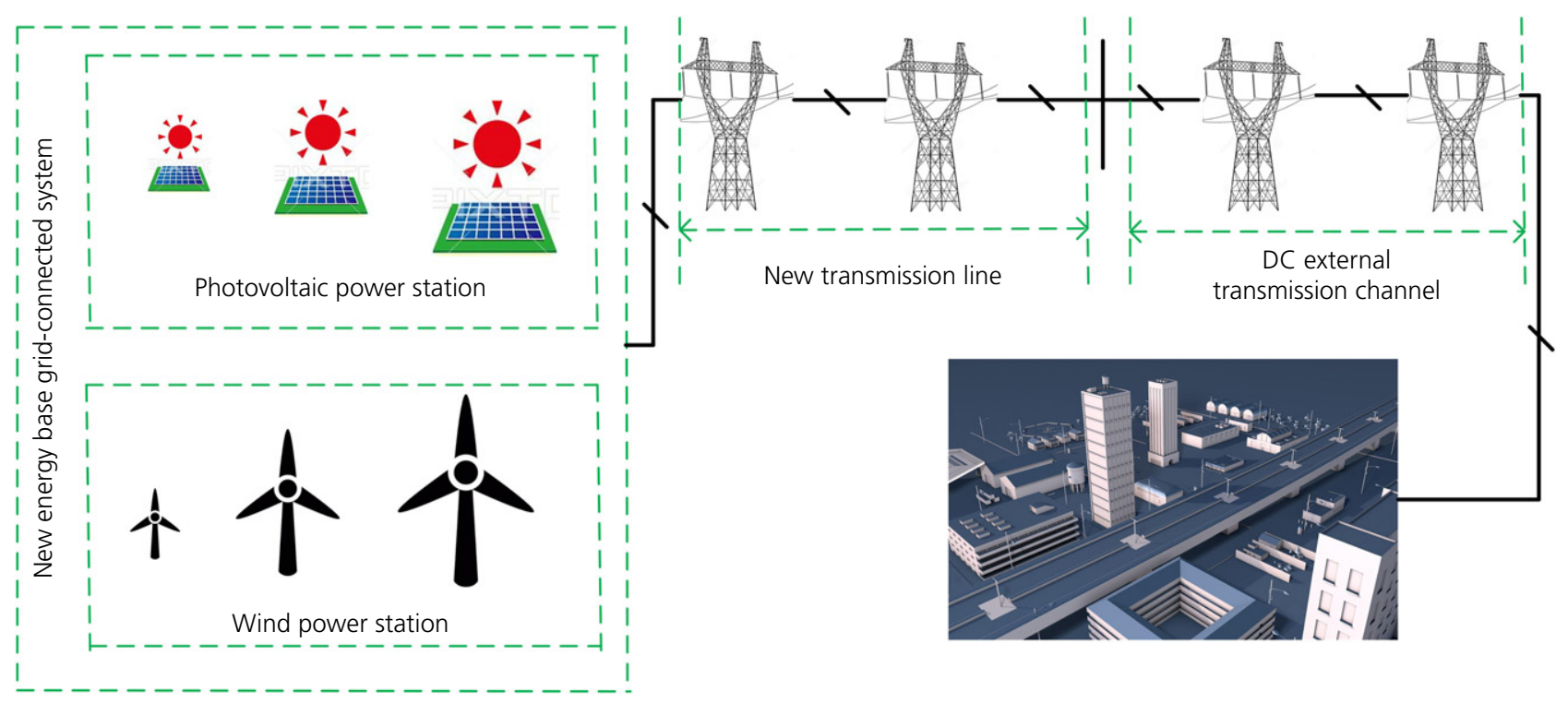

Figure 1. Schematic representation of a grid-connected system of a new energy base

Table 1. Advantages and disadvantages of various grid connection modes

\begin{tabular}{|c|c|c|c|}
\hline Transmission system & Scheme 1 & Scheme 2 & Scheme 3 \\
\hline Grid connection mode & $A C$ & LCC-DC & VSC-DC \\
\hline Conditions for grid connection & Need synchronisation & Synchronous/asynchronous & Synchronous/asynchronous \\
\hline Conveying distance & Closer distance & Long-haul & Medium distance \\
\hline $\begin{array}{l}\text { Starting conditions of transmission } \\
\text { system }\end{array}$ & $\begin{array}{l}\text { No external power } \\
\text { support required }\end{array}$ & External power support required & Black start \\
\hline System control strategy & No control strategy & Active power control strategy & Power decoupling control strategy \\
\hline Requirements for $\mathrm{AC}$ system & $\begin{array}{l}\text { Need the support of } \\
\text { strong } A C \text { system }\end{array}$ & Need the support of strong AC system & Weak/no support of AC system \\
\hline The problem of commutation failure & No commutation failure & Possible commutation failure & No commutation failure \\
\hline The problem of voltage drop & Serious voltage drop & Small voltage drop & Very small voltage drop \\
\hline Converter/transformer voltage level & Low voltage level & High voltage level & High voltage level \\
\hline Demand for reactive power & Higher demand & Higher demand & $\begin{array}{l}\text { Self-existing reactive power } \\
\text { compensation capacity }\end{array}$ \\
\hline
\end{tabular}

two grid connection modes. The transmission capacity of VSC has been greatly improved. It has obvious advantages in the application of new energy DC grid connection and high feasibility in terms of engineering. Due to the small initial investment, an AC grid-connected system has certain advantages. In practical engineering, the factors such as grid conditions, scale of wind farm construction, project cost, operation and maintenance, system loss and so on should also be taken into account.

\section{New energy multi-investment grid-connected economic evaluation}

According to the current development of new energy, the capacity of many regional large-scale new energy bases will reach at least 1 million $\mathrm{kW}$ in the future, far exceeding the consumption level of the local power grid. The economic evaluation of the two feasible grid-connected modes is given below.

\subsection{Comparison of $\mathrm{AC}$ and DC transmission technology}

The transmission capacity of the DC transmission line considers that the voltage drop does not exceed $5 \%$ of the rated voltage. The loss of the DC transmission line comes from corona discharge, skin effect and reactive power loss. The loss of the DC transmission line mainly comes from resistance and corona loss (Liang et al., 2013). According to Ullman formula (Yao et al., 2018), the voltage of the DC line is $(+330 \mathrm{kV}$ ) 
and that of the $\mathrm{AC}$ line is $320 \mathrm{kV}$. The calculation results show that under the same transmission distance, the transmission capacity of the DC line is much larger than that of the AC line.

\subsection{Economical comparison of $\mathrm{AC}$ and DC transmission}

The annual cost method is used to compare economy, mainly considering the annual cost of project investment, annual operation and maintenance costs, and transmission loss costs of AC and DC transmission channels (He et al., 2017; Xia et al., 2015; Yang et al., 2015)

1. $C_{\text {year }}=c_{\text {invest }} C_{\text {eng }}+C_{\text {opti }} C_{\text {eng }}+L_{\text {trayear }} h_{\text {year }} p$

where $C_{\text {year }}$ is the annual fee, $c_{\text {invest }}$ is the annual average of the engineering current rate, $C_{\mathrm{eng}}$ is the total project cost, $C_{\mathrm{opti}}$ is the engineering annual maintenance cost, $L_{\text {trayear }}$ is the annual transmission total loss, $h_{\text {year }}$ is the annual utilisation hours of the transmission channel and $p$ is the selling electricity price.

In addition, $C_{\text {eng }}$ and $L_{\text {trayear }}$ can be given by Equations 1 and 2

2. $C_{\text {eng }}=C_{\mathrm{cs}}+C_{\text {line }} D_{\text {line }}$

where $C_{\mathrm{cs}}$ is the investment in infrastructure equipment such as converter station and transformer station, $C_{\text {line }}$ is the average cost per kilometer of the transmission line, $D_{\text {line }}$ is the length of the transmission line.

3. $L_{\text {trayear }}=L_{\mathrm{Rline}}+L_{\mathrm{al}}+L_{\mathrm{scl}}+L_{\mathrm{Tcap}} T_{\text {conrat }}$

where $L_{\mathrm{R} \text { line }}$ is the loss caused by line resistance during transmission, $L_{\mathrm{al}}$ is the corona loss of line, $L_{\mathrm{scl}}$ is the line loss caused by series compensation capacitance, $L_{\text {Tcap }}$ is the transmission capacity of line and $T_{\text {conrat }}$ is the loss rate of commutation/substation.

When the installed capacity of new energy base reaches $1000 \mathrm{MW}$, the total loss of the AC and DC transmission project is considered, and the total cost of the $330 \mathrm{kVAC}$ and DC transmission project is calculated according to the Ullman formula and Equations 1-3. The results show that AC power transmission is suitable for short-distance grid connection, but with the increase of transmission distance, a large amount of reactive power compensation equipment needs to be compensated in series to increase the investment. VSC-DC transmission is suitable for long-distance grid connection, and the investment cost of the converter station is large. However, the longer the transmission distance, the lower the annual cost of the whole project. The ratio of the annual cost of $\mathrm{AC}$ grid connection to the annual cost of VSC DC grid connection is defined as the ratio coefficient of power transmission distance. The calculation results show that when the transmission distance is $100 \mathrm{~km}$, the ratio coefficient of transmission distance is 1 , which shows that the engineering cost of the two schemes is equal. In the area of 'Three North' with weak grid structure, considering that many new energy bases are connected to the grid by newly built transmission lines, the grid-connected capacity is about $1200 \mathrm{MW}$, the transmission distance is within $120-550 \mathrm{~km}$, and the transmission distance coefficient is more than 1 , so the advantage of using a VSC DC grid-connected system is obvious.

Considering 25 years of operation, the annual discount rate of the project is $9 \%$, and the operation and maintenance rate is $2 \%$. The calculation results show that the annual investment value, annual operation and maintenance cost, annual transmission loss cost and the annual cost of a VSC grid-connected system are far lower than those of an AC grid-connected system when the transmission distance of the two gridconnected modes is $200 \mathrm{~km}$.

\section{System design}

\subsection{System topology design}

According to Figure 1, the model is built using DIgSilent software. The topological structure of the two new energy grid-connected systems is shown in Figure 2. VSC voltage

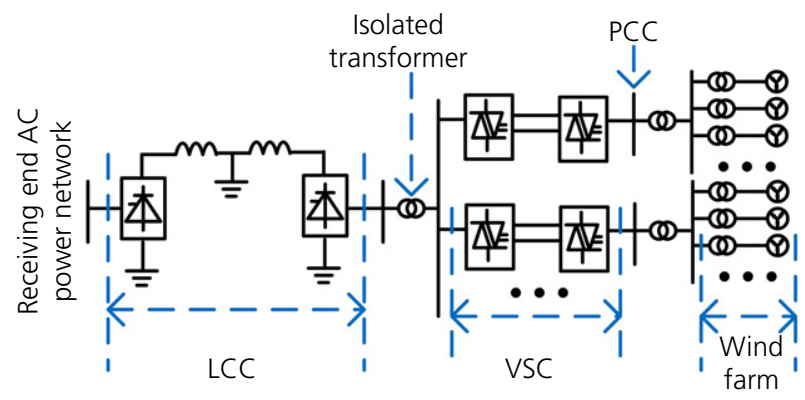

(a)

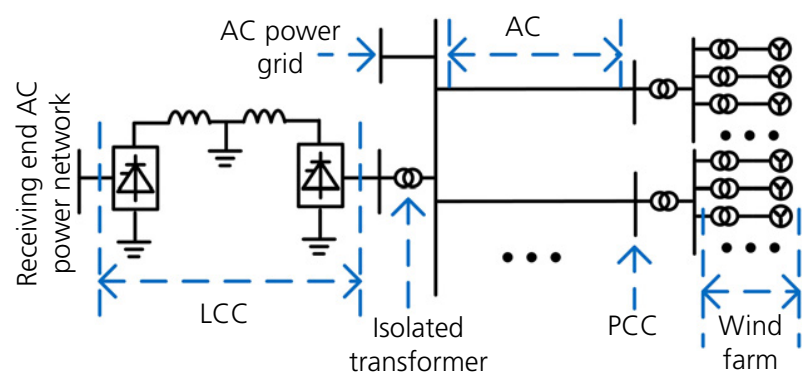

(b)

Figure 2. Schematic representations of (a) a new energy multi-infeed DC grid-connected system, (b) a new energy AC grid-connected system 
level is low, while LCC voltage level is high. It can isolate fault voltage and current and solve the bottleneck of a small capacity of DC/DC converter through a large-capacity isolation transformer (Zhang et al., 2019). Only the wind farm is shown in the figure, and the connection mode of the photovoltaic power station is the same.

\subsection{System configuration scheme}

The two schemes are designed to have the same three new energy bases. The total capacity of two wind power bases is $2000 \mathrm{MW}$, and the photovoltaic base is $500 \mathrm{MW}$. Through three newly built AC lines and VSC DC lines, the power is transmitted a distance of $200 \mathrm{~km}$. The VSC wind farm side is controlled by constant $\mathrm{AC}$ voltage, the receiving end is controlled by constant DC voltage and equipped with chopper angle control. The isolation transformer capacity is $2400 \mathrm{MW}$, and the ratio is $330: 350 \mathrm{kV}$. The AC line voltage level is $330 \mathrm{kV}$, which is regulated by series compensation only. There is no control mode. Reactive power compensation is $350 \mathrm{Mvar}$. The LCC is $1100 \mathrm{~km}$ long. The output DC channel of wind power is controlled by constant DC and constant delay angle, and the inverter side is controlled by constant DC current and constant off angle. The LCC multi-feed converter station needs to consider the support of a certain capacity AC system, but the scale is small.

\section{Simulation analysis}

\subsection{Static stability analysis}

The static characteristics of the system are studied by establishing the time-series output model of a wind farm considering wind speed change and the time series output model of photovoltaic power station considering light. The model fully considers the asynchronism of time series output of regional new energy. Then, based on the continuous power flow method and DIgSilent, the stability of the system in normal operation mode is analysed.

The normal steady-state conditions of the simulated new energy multi-feed into the grid are verified by quasi-dynamic simulation. The transmission power curves of the three new energy bases are shown in Figure 3. According to Figure 3, the trend of power transmission in the three new energy bases is different. The actual output of new energy through VSC grid connection is significantly higher than that of AC grid connection.

The power of each large wind farm and photovoltaic power station converges at the LCC converter station. Due to the fluctuation of new energy sources, the LCC rectifier station needs to supplement power from the AC system. In an AC grid-connected system, the main network needs to supplement more active power, and the main network provides a

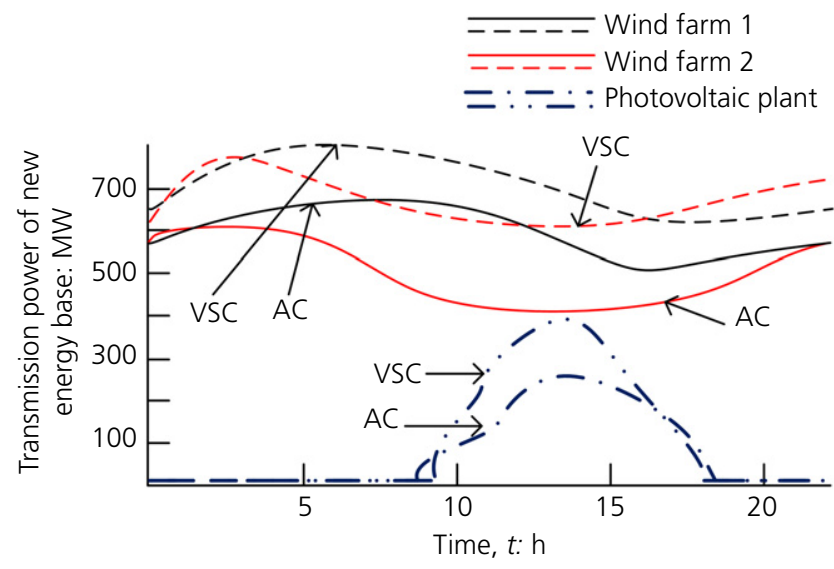

Figure 3. Active power output of each new energy base

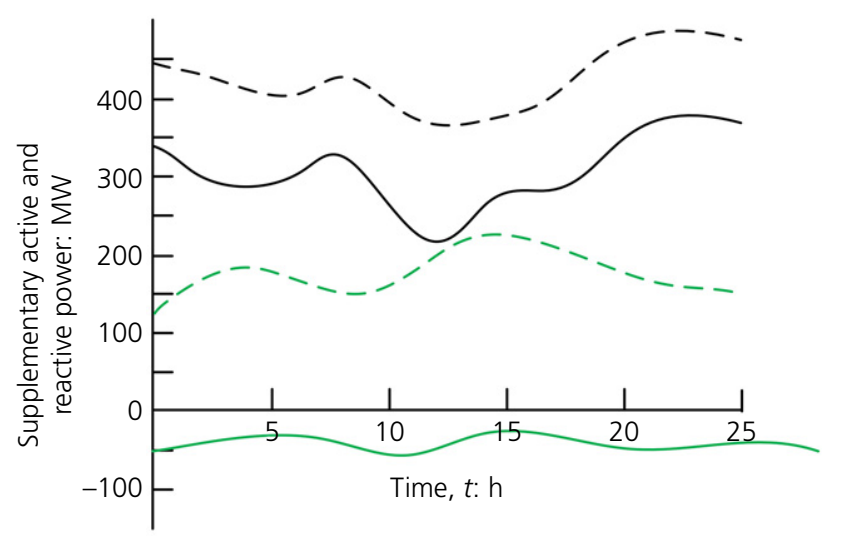

- - - Supplementary active power of power network

---- Supplementary reactive power of power network

Figure 4. New energy base absorbs power from the AC system

large amount of reactive power for LCC DC commutation. When multi-feed VSC is connected to the grid, the loss of new energy is very small, and reactive power compensation is provided by itself, which relies less on the AC system. Figure 4 shows the amount of electricity absorbed from the AC system by new energy sources due to insufficient volatility output.

The output fluctuation of new energy is large, which has a great impact on the voltage stability of the transmission system. The two schemes designed in this paper have the ability to suppress the voltage fluctuation of new energy. First, the output of a single fan in a wind farm is combined through a first-order complementary. Second, the secondary output complementarity of wind farm level is realised at the supply 


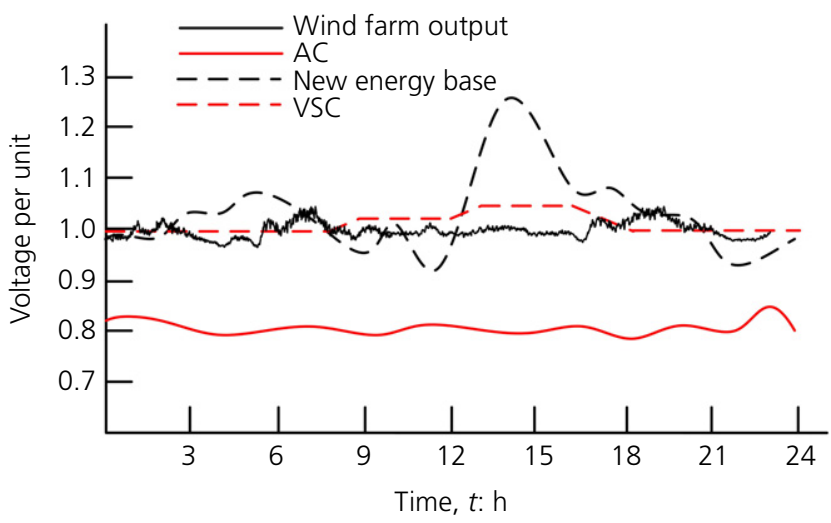

Figure 5. Voltage of transmission line in the wind farm

end of the energy base. Finally, through AC and DC transmission channels, the three-level complementarity of regional new energy bases can be achieved. For a photovoltaic base, the available hours of photovoltaic can be greatly increased by three-stage complementarity only during the daytime. In the two schemes, it is obvious that the voltage of a multi-feed VSC DC grid-connected system is more stable. When new energy is connected to the AC grid, the active power shortage is serious, and the voltage drop of its important buses and $\mathrm{AC}$ lines is large. Even if reactive power compensation equipment is installed on the transmission line, the effect is not ideal compared with that of VSC DC grid connection. Figure 5 shows the voltage fluctuation of transmission lines in wind farms within $24 \mathrm{~h}$.

Both $\mathrm{AC}$ and $\mathrm{DC}$ grid-connected systems have no power flow non-convergence under normal operating conditions with new energy access. Overall, the advantages of VSC gridconnected systems are higher than AC grid-connected ones. In this case, the system is stable and conducive to new energy output.

\subsection{Transient simulation analysis}

Suppose a three-phase short-circuit fault occurs at the bus of a wind farm in a wind power base. The capacity of the fault wind farm is $150 \mathrm{MW}$, and the fault sequence is as follows: initially, the system runs normally. At $0 \mathrm{~s}$, the PCC bus of the wind farm has a three-phase short-circuit fault. The fault lasts for $0.18 \mathrm{~s}$, then the fault is cleared, and the simulation ends at $0.42 \mathrm{~s}$.

The output of the DC channel in this scenario is shown in Figure 6. When an AC grid-connected mode fails, the voltage of an $\mathrm{AC}$ bus in the rectifier side of the LCC DC channel decreases, and the rectifier side enters the fixed minimum trigger angle control to improve DC voltage. The inverter

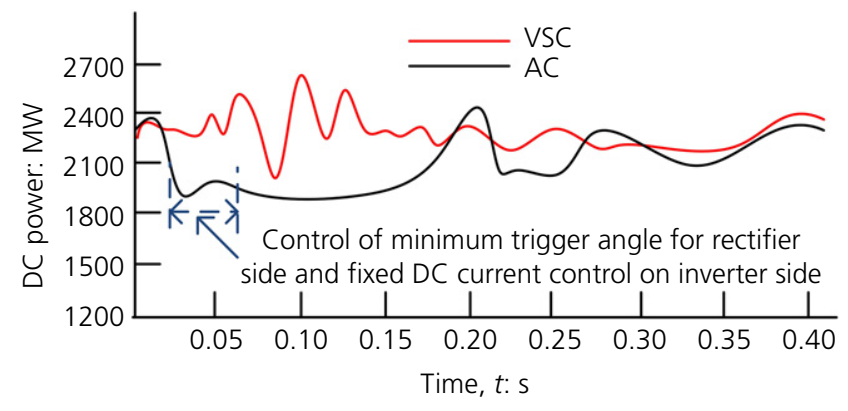

Figure 6. Active power curve of the DC grid-connected system

side adopts the fixed DC current control and reduces the setting current. The system reaches a new balance point. However, the power shortage, the power supply reduction and the recovery occur after the fault clearance. When the multifeed VSC is connected to the grid, the fault has little effect on the $\mathrm{AC}$ system voltage. Because the DC short-circuit current recovers quickly, it only causes the short-term power fluctuation of the system. Then the system voltage returns to normal, and the LCC DC channel returns to normal transmission power.

During the fault, the fault wind farm output is seriously damaged. The simulation results show that when the wind farm is connected to the grid by AC mode, the voltage of PCC AC bus decreases and oscillates. Because the short-circuit current transient changes greatly, the recovery is slow, and the wind farm cannot achieve active power smooth output and maintain voltage balance by absorbing a large amount of reactive power. Even after the fault is removed, it is difficult to restore the smooth output of power for a short time. In the case of VSC grid connection, when the PCC bus voltage is unstable, the rectifier side adopts constant $\mathrm{AC}$ voltage control to maintain the grid voltage of the wind farm side; the inverter side adopts constant DC voltage control to control the reactive current under priority. By limiting the active current and increasing the reactive compensation, the power balance of the power grid is realised, and finally the stability is improved. Figure 7 shows the dynamic characteristics of a faulty wind farm.

During the fault, the faulty wind farm PCC AC bus voltage imbalance is transmitted to other normal wind farms. When AC is connected to the grid, the output of other normal wind farms is seriously damaged. The doubly fed unit gives up the active output and emits reactive power. The VSC gridconnected voltage and current are only affected by short-term effects and recover quickly. Figure 8 shows the PCC AC bus voltage curve, short-circuit current curve, active power curve and reactive power curve of the normal wind farm. 


\section{Energy}

Volume 174 Issue 2
Feasibility study on new energy

multi-feed direct current grid connection

Guo, Zhang and Zhao
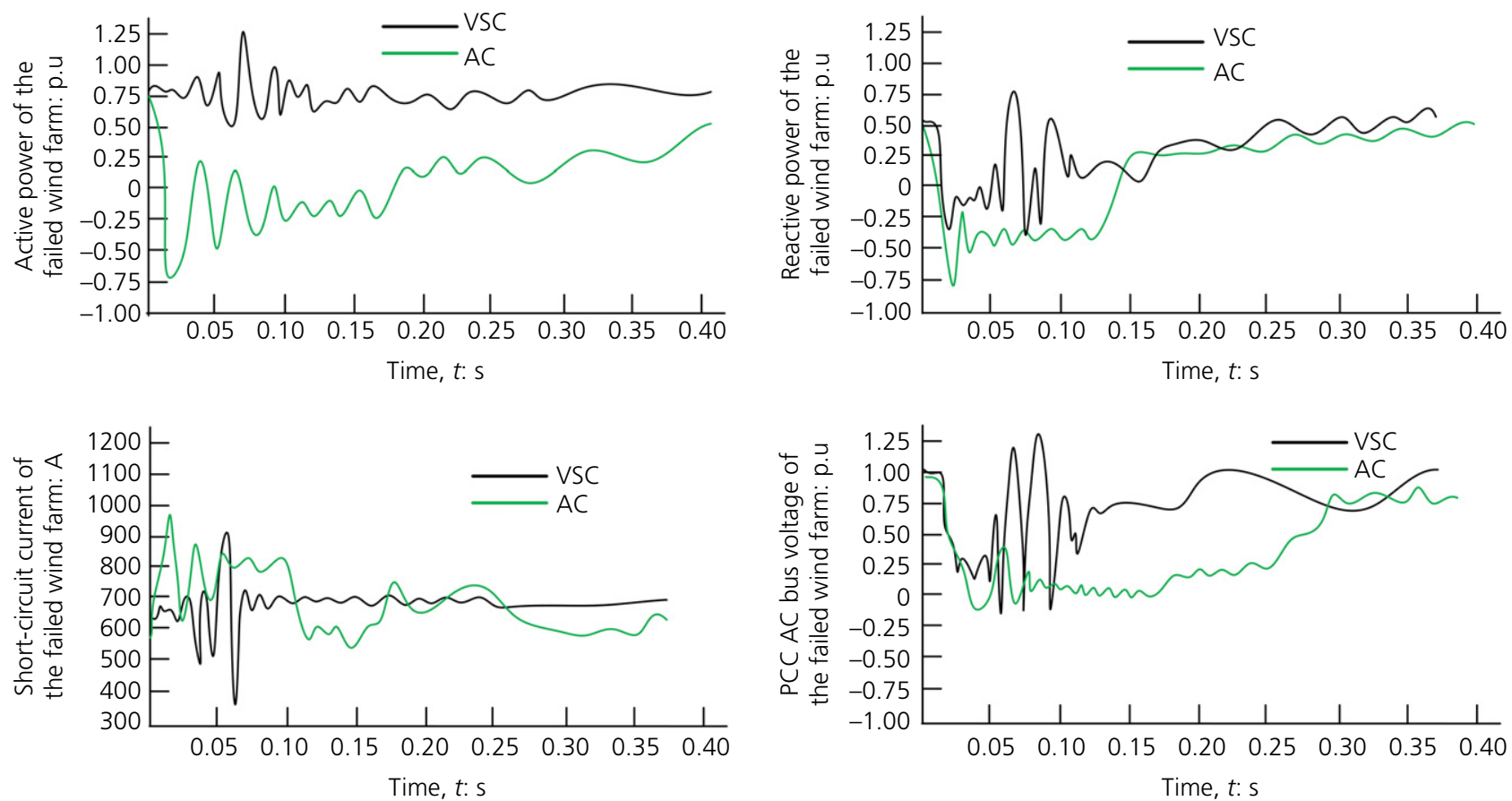

Figure 7. Fault state curve of the wind farm
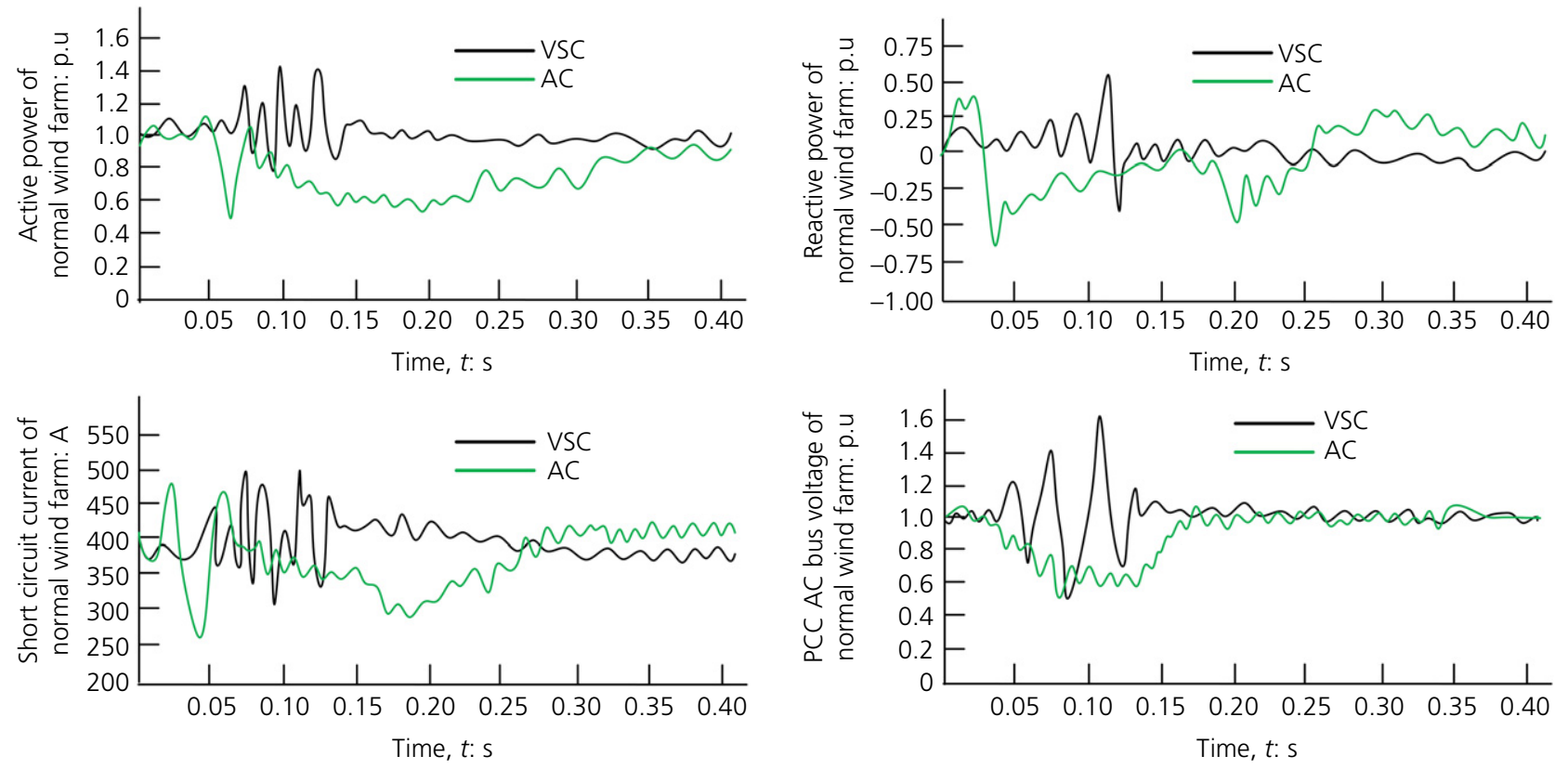

Figure 8. Normal state curve of the wind farm 

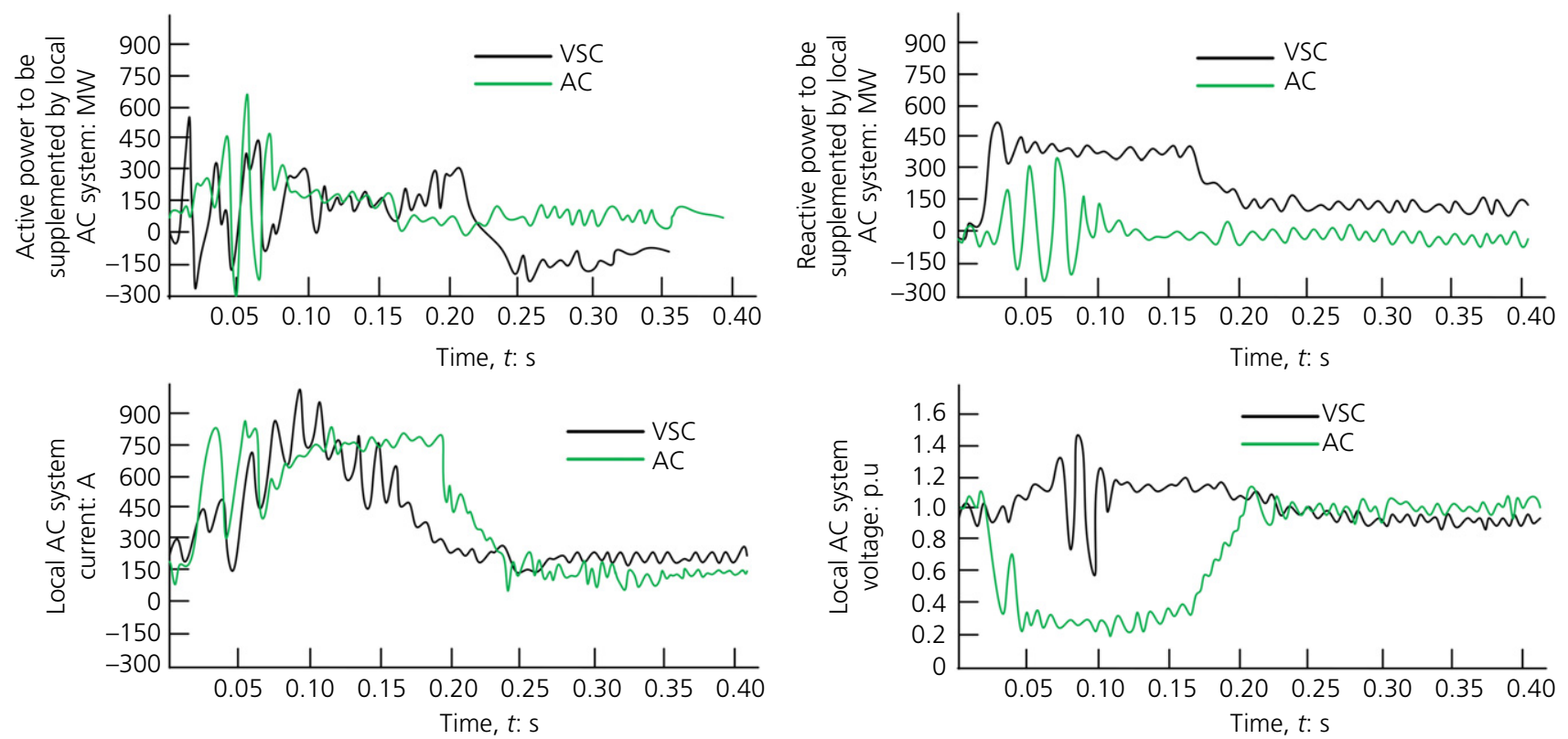

Figure 9. State curve of an AC power grid in the case of wind farm failure

During the fault, in order to maintain the normal operation of the LCC DC channel, the local AC system needs to supplement the appropriate amount of active power and reactive power, and its voltage current has a greater impact. AC grid connection requires a large amount of active power and reactive power to be added, which greatly affects the stability of the system. The VSC grid-connected system is extremely secure. Only a large amount of active and reactive power is added at the beginning of the fault. After the system is restored to equilibrium, it no longer depends on the AC system. Figure 9 shows the dynamic characteristics of the transmitting-end $\mathrm{AC}$ system.

The transient characteristics of photovoltaic power plants caused by faults are similar to those of wind farms. Generally, the fault-recovery ability of the system is affected by the grid connection mode. The long-distance transmission network of AC system is weak and its stability is poor. The VSC DC system has the advantages of small loss, flexible control strategy, strong fault voltage and current-regulation ability. By adjusting the parameters through simulation, it is concluded that the stability of the system is mainly affected by the grid-connected mode, control strategy, multi-feed-in AC system and the strength of the receiving-end AC system. In an VSC DC grid-connected system, each component needs to have a short-term overvoltage and overcurrent tolerance. In the follow-up study, power flow control devices and improved control strategies can be considered to enhance the stability of the system.

\section{Discussion}

The geographical distance between the energy-rich areas in north-west China and the economically developed areas in south-east China is far. In this case, if the traditional AC outgoing mode is adopted, there are some problems, such as small capacity, large loss and great influence on the regional AC system. For this reason, this study proposes a scheme of multifed VSC grid connection and LCC transmission for a regional large energy base.

The transient characteristics and static characteristics of multi-infeed DC and traditional AC grid-connected modes in fault process are compared and analysed. The results show that the multi-infeed DC grid-connected mode, which is used for a large number of regional new energy grid-connected systems, can suppress the intermittent fluctuation of new energy, increase the consumption of new energy and reduce the dependence of the traditional LCC DC transmission end on the AC power grid.

The time-domain simulation analysis is carried out for the multi-regional large-scale new energy base which adopts multi-feed DC grid connection and traditional AC grid connection. The results show that the new energy can be more complementary in time and region by using multi-feed DC grid connection and three-stage stabilisation. At this time, the consumption of new energy has increased by about $25 \%$, and the dependence on the AC system at both ends has been 
weakened. Under the conditions of the traditional AC gridconnected systems in a new energy base, the transient process of fault short-circuit current takes a long time and fluctuates greatly. When the new energy base adopts multi-feed DC grid connection, the fault short-circuit current only oscillates for a short time and recovers very quickly.

In addition, it should be pointed out that in order to control the influence of short-circuit fault current on the system, it can be realised by adding a power flow control device and improving the control strategy. The above analysis provides a reference for the follow-up study of the multi-infeed DC transmission mode of a regional large energy base.

\section{Conclusion}

In this study, a multi-infeed DC transmission scheme is proposed to solve the problem of long-distance energy transmission in regional large-scale energy bases. Through the technical feasibility analysis, economic evaluation, static and steady-state analysis, the following conclusions are obtained. First, when the transmission distance is more than $100 \mathrm{~km}$, the multi-infeed DC transmission mode is far superior to other transmission modes in terms of technical performance and economic performance. In addition, compared with other transmission modes, the multi-infeed DC transmission scheme with three-level smoothing has less impact on the AC power grid and a higher consumption level of new energy. Finally, in the process of fault recovery, compared with other transmission systems, the multi-infeed DC system has a shorter transient time of electric quantity and a faster recovery of stable state.

\section{Acknowledgement}

The authors acknowledge the National Natural Science Foundation of China, Foundation item (51667018), which funded this project.

\section{REFERENCES}

Cao Y, Li P, Yuan Y et al. (2014) Analysis on accommodating capability of renewable energy and assessment on low-carbon benefits based on time sequence simulation. Automation of Electric Power Systems 38(17): 60-66.

Dong XZ, Tang Y, Bu GQ et al. (2019) Confronting problem and challenge of large scale AC-DC hybrid power grid operation. Proceedings of the CSEE 39(11): 3107-3118.

He JH, Li ZC, Wang XJ and Chen N (2017) Optimal power flow algorithm for hybrid AC/DC power systems considering power loss of converter and voltage-droop control. Automation of Electric Power Systems 41(22): 48-55.

Li CH, Zhan P, Wen JY et al. (2015) A multi-terminal VSC-HVDC system control strategy for large wind farms integration. Automation of Electric Power Systems 39(11): 1-7.

Li SH, Wang XL, Peng Z, Li T and Wang JH (2016) Hybrid multi-terminal integration of parallel FB-MMC tapping station into LCC-HVDC transmission link. Power System Technology 40(9): 2795-2802.

Li DY, Wu JL, Zhang H et al. (2017) Comprehensive evaluation index of DC fault ride-through capability for novel voltage source converter. Power System Technology 41(10): 3201-3209.

Li P, Wang WS, Liu C et al. (2018) Economic assessment of Zhangbei VSC-based DC grid planning scheme with integration of renewable energy and pumped-hydro storage power station. Proceedings of the CSEE 38(24): 7206-7214.

Liang HQ, Wu X and Liang XM (2013) Operation losses and economic evaluation of UHVAC and HVDC transmission systems. High Voltage Engineering 39(3): 630-635.

Liu DW, Huang YH, Wang WS and Guo JB (2011) Analysis on provincial system available capability of accommodating wind power considering peak load dispatch and transmission constraints. Automation of Electric Power Systems 35(22): 77-81.

Liu Y, Zhou M, Xiang M and Zhang ZF (2013) Total transfer capability calculation for regional power systems with HVDC connected with large scale wind power. Power System and Clean Energy 29(2): 48-53.

Liu J, Yao W, Wen JY et al. (2014a) Prospect of technology for large-scale wind farm participating into power grid frequency regulation. Power System Technology 38(3): 638-646.

Liu ZY, Zhang QP, Dong C, Zhang L and Wang ZD (2014b) Efficient and security transmission of wind, photovoltaic and thermal power of large-scale energy resource bases through UHVDC projects. Proceedings of the CSEE 34(16): 2513-2522.

Liu S, Yu J, He ZY et al. (2018) Research on the topology and characteristic of multi-terminal HVDC based on VSC and LCC. Proceedings of the CSEE 38(10): 2980-2988.

Niu DX, Li JF, Wei LJ and Chi YN (2016) Study on technical factors analysis and overall evaluation method regarding wind power integration in trans-provincial power grid. Power System Technology 40(4): 1087-1093.

Peng LB, He J, Xie KG et al. (2017) Comparison of reliability and economy between UHVAC and UHVDC transmission systems. Power System Technology 41(4): 1098-1105.

Shu YB, Zhang ZG, Guo JB and Zhang ZL (2017) Study on key factors and solution of renewable energy accommodation. Proceedings of the CSEE 37(1): 1-8.

Tang GF, He ZY and Pang H (2013) Research application and development of VSC HVDC engineering technology. Automation of Electric Power Systems 37(15): 3-14.

Wang XF, Wei XH, Ning LH and Wang XL (2014) Integration techniques and transmission schemes for off-shore wind farms. Proceedings of the CSEE 34(31): 5459-5466.

Xia JL, Mao X, Ke DP et al. (2015) Applicable scope of AC and DC power transmission based on comprehensive evaluation. Electric Power Automation Equipment 35(3): 120-126.

Xie XR, Liu HK, He JG, Zhang CY and Qiao Y (2016) Mechanism and characteristics of subsynchronous oscillation caused by the interaction between full-converter wind turbines and $\mathrm{AC}$ systems. Proceedings of the CSEE 36(9): 2366-2372.

Yang H, Liao QF, Liu DC and Ma WY (2014) Analysis of DC grid technology based on large-scale renewable energy access. East China Electric Power 42(4): 669-673.

Yang D, Cheng HZ, Yao LZ and Zeng PL (2015) Research review on AC/DC hybrid system with multi-terminal HVDC. Power System Technology 39(8): 2201-2209. 
Yao LZ, Wu J, Wang ZB, Li Y and Lu ZX (2014) Pattern analysis of future HVDC grid development. Proceedings of the CSEE 34(34): 6007-6020.

Yao LZ, Liu YZ, Yang B and Chen N (2018) Research on DC collection and transmission for large scale renewable energy generation clusters. Electric Power 51(1): 36-43.
Zhang Y, Jing L, Wu XZ, Wu W and Wei MH (2019) A novel DC autotransformer applied to DC grids. Power System Technology 43(9): 3297-3304.

Zheng C, Ma SY, Sheng CH et al. (2013) Mechanisms and countermeasures for stability deterioration caused by interactions between $\mathrm{AC}$ and HVDC systems. Automation of Electric Power Systems 37(21): 3-8.

\section{How can you contribute?}

To discuss this paper, please email up to 500 words to the editor at journals@ice.org.uk. Your contribution will be forwarded to the author(s) for a reply and, if considered appropriate by the editorial board, it will be published as discussion in a future issue of the journal.

Proceedings journals rely entirely on contributions from the civil engineering profession (and allied disciplines). Information about how to submit your paper online is available at www.icevirtuallibrary.com/page/authors, where you will also find detailed author guidelines. 